division the bundles carrying the fibres for the circumflex and musculo-cutaneous nerves can be easily separated from each other and electric stimulation demonstrates which bundle is functioning. In a case of infantile paralysis in which the deltoid and spinati muscles were paralysed, but the biceps, brachialis anticus and supinator longus were acting, they in this manner separated the bundle in the fifth primary division, cut the degenerated part and anastomosed it with the sixth cervical anterior primary division. This case was recently shown with marked recovery of power at the Clinical Society of London, three years after the operation.

Anastomosis is of course the only operation in infantile spinal paralysis. E. J., aged two years and two months, suffered from infantile palsy when one year old, which left him with wasting and paralysis of the deltoid, supra- and infra-spinatus, and the flexors of the forearm. The muscles did not react to faradism but gave a fair response to the constant current. In October, 1905 , the plexus was exposed; the fifth primary division was found to be much wasted, of about one-third the size of the sixth, and gave no response to electrical stimulation. The sixth looked normal and stimulation caused strong contraction of the serratus and pectoralis major. The fifth division was then cut and its distal end placed in a longitudinal division made with the sixth. Healing took place by primary union. No alteration in power was noticed by August, 1906.

W. D. J.-This was a case of neuritis with the symptoms mentioned in the text. On Augnst 16th, 1905, the plexus was exposed without much difficulty. A rather delicate cicatrix surrounded the junction of the fifth and sixth primary division; this was closed up and the three distal branches were clearly exposed. Electrical stimulation of the fifth gave a negative response to deltoid, spinati muscles, biceps and brachialis anticus, but a feeble contraction of the supinator longus and radial extensors. The sixth gave a vigorous contraction of triceps, pectorales, and latissimus dorsi. The fifth trunk was divided longitudinally into two unequal halves; the smaller part gave a feeble contraction of the supinator longus, the larger gave no response. This was accordingly divided and anastomosed with the sixth. On August 31st, 1906, our note reads: "The biceps, brachialis anticus, and supinator longus show distinct recovery and the reaction to faradism is present; to galvanism there is a brisk contraction with K.C.C.>A.C.C. The posterior fibres of the deltoid react both to F. and G. K.C.C.> A.C.C. contraction fairly brisk. The anterior fibres do not react to faradism and give a feeble response to galvanism. A.C.C. > K.C.C. contraction sluggish. The infra- and supraspinati are powerless, but slight external rotation of the humerus can be performed to a moderate extent by the posterior fibres of the deltoid. Appears to have slight loss of epicritic sensation over the outer preaxial border and complains of a slight burning sensation."

In the case of $\mathrm{E}$. $\mathrm{E}$. with symptoms described in the text, operation performed on Sept. 14th, 1904, was not undertaken till four years after the injury. On exposing the plexus, a very dense fibrous matting was found uniting the upper roots and their branches. It was impossible fully to clear this away and the scar appeared too long to risk an exsection extending for at least two and a half centimetres. Electrical stimulation, as far as this could be ascertained, gave no response in the distal branches, but the seventh primary division gave strong extension of the elbow and wrist and lateral rotation of the humerus. The nerves beyond the cicatrix were therefore cut and anastomosed with the seventh. On August 31st, 1906, our note reads: "There is no improvement in muscular power; full reaction of degeneration present. Sensation : can feel pin-prick everywhere, but loss of touch to cotton-wool in the original area of anæsthesia-i.e., return of protopathic sensation."

From a survey of the literature one learns that by almost every method of junction success has been attained. No one surgeon can speal authoritatively from his limited experience of operations upon man, and operations upon animals are more suggestive than convincing. Clearly, where it is possible, end-to-end junction is the ideal method. In operations upon the brachial plexus, however, this form of junction is only occasionally available, as the cicatricial surroundings increase the difficulty of stretching the nerves, and any pull upon the nerve makes the suture less effective. Failing end-to end suture one must be guided, as Spitzy says, by the condition we find.

Nerve transplantation, nerve anastomosis, and nerve crossing as suggested by Sherren is a satisfactory classifition and it will be well to exclude the term "nerve grafting" from the nomenclature. Sherren in an exhaustive article discusses the relative merits of transplantation of human nerve (homo-transplantation) and the transplantation of nerves from animals (hetero-transplantation). The results are much better in auto- and homo-transplantation than in hetero-transplantation. Of eight cases, only three were reported sufficiently long after operation to admit of recovery. Of these, two completely recovered and one was no better 17 months after operation, but of 22 instances of hetero-transplantation 16 were reported at a sufficient interval after operation to admit of some recovery. By making every liberal allowance only six cases outi of 16 could be reported as successes. The clinical results are therefore against hetero-transplantation and this bears out the observation of Merzbacher, ${ }^{17}$ Forssman, ${ }^{18}$ and others that transplantation of nerves in animals of the same species was more successful than when animals of a different species were employed.

In nerve anastomosis it is endeavoured to bring the axis cylinders into end-to-end contact with some of those of sound nerve. Sherren, excluding the cases in which the operation was performed on the facial nerve, collected 25 examples. Twelve were allowed a sufficient time for some recovery to occur. Of these 12 cases only two were failures, some improvement taking place in all the others. Nerve crossing has been employed mainly in facial paralysis, and of eight cases reported voluntary power in the facial was restored. Until further operations have been performed it will be difficult accurately to generalise as to the method of election, but in operations on the brachial plexus we are scarcely justified in doing more than (a) end-to-end junction; (b) nerve anastomosis and (c) auto- or homo-implantation. Spitzy, ${ }^{19}$ who has had perhaps the largest operative experience, lays the greatest stress upon technique as being of more importance than the particular form of junction effected, but he favours the imbedding of the pathological into the healthy nerve. He prefers the slit to be longitudinal and recommends that it should be tied longitudinally and loosely. Asepsis should be rigid, and assistants called on to register electric reactions at the time of operation should attend to all precautions. The nerves should be most gently handled and the stitching should be sufficiently accurate to prevent the ingress of fibrous tissue between the axis cylinders. Where, from extensive dissection in fibrous tissue, adhesions may be feared, the nerve ends can be surrounded by sterile foil. When the operation has been completed and the wound healed massage and the postural shortening of lengthened muscles should be practised.

\section{WATER GAS, CARBURETTED WATER GAS, AND CARBON MONOXIDE POISONING.}

By JOHN GLAISTER, M.D. GLASG., D.P.H. CANTAB., F.R.S. EDIN., \&C.,

REGIUS PROFESSOR OF FORENSIC MEDICINE AND PUBLIC HEALTH IN

THE UNIVERSITY OF GLASGOW ; EXAMINER IN THE UNIVERSTTY

OF BIRMINGHAM ; AND MEDICO-LEGAL EXAMINER IN

CROWN CASES, GLASGOW.

(Concluded from $p$. 1582.)

Rationale of Water Gas Poisoning.

AIR which contains minute percentage proportions of carbon monoxide, as, for example, 0.05 per cent., does not seem to produce when inhaled ror some hours any visible illeffect, chiefly owing to the inhibitory influence which oxygen in combination with the hæmoglobin of the blood exercises upon the union of carbon monoxide with the hæmoglobin. At the same time, however, while no direct ill-effects may be apparent from short inconsecutive periods of inhalation of air so contaminated, it must not be concluded that constant living in such an atmosphere may be done with impunity. Corfield and other writers have reached the conclusion that probably more depreciation of health is

16 Sherren : Edinburgh Medical Journal, October, 1906. 17 Merzbacher: Neurologisches Centralblatt, 1905.

18 Forssman : Beitrage zur Allgemeinen Pathologie und Pathologischen Anatomie. 1900, S. 407.

19 Spitzy: Zeitschrift fur Orthopädische Chirurgie, Bäde xiii., xiv., and xv.; Archiv fir Orthopadische und Unfallchirurgie, Band iii., 
produced by minute leakages of coal gas in dwellings than by so.called sewer air or sewer gas. My experience tends in a like direction.

The compound formed, carboxy-hæmoglobin, is a stable compound, and it is the formation of this compound which entitles us to pronounce carbon monoxide a cumulative poison. But the inhibitory influence of oxygen upon its union with the colouring matter of the blood has, after all, a very limited operation; indeed, it is largely overcome, or entirely fails, when the percentage amount of carbon monoxide in the air is increased, because we find the carbon monoxide supplanting the oxygen in the blood and after the formation of the carboxg-hænoglobin renders the oxygen unable to dissociate it from the hæmoglobin. But a remarkable fact is observable where by experiment carbon monoxide is administered so that it may be as fully absorbed by the blood as it can be, and that is that there still remains a proportion of oxygen, amounting from one-sixth to onefifth, in combination with the hæmoglobin. The important question which arises in the treatment of cases of carbon monoxide poisoning is, How may this gas which is in combination with the hæmoglobin be got rid of or dissociated? Experience has proved that this is not easy. Donders asserted that carboxy-hæmoglobin is capable of being dis. sociated, and G iglio ${ }^{2}$ has proved, what experience has likewise demonstrated, that carbon monoxide is not oxidised within the animal body.

Haldane's account of experiments on himself with inhalations of air containing from 0.044 to 0.046 per cent. of carbon monoxide shows that little serious effect was apparent even at the end of four hours' inbalation, the only noteworthy symptoms being slight hyperpncea and slight palpitation of the heart on ranning upstairs. Bat when the percentage was increased to 0.21 per cent., as in another experiment, toxic symptoms became much more marked. After 34 minutes' inhalation slight feelings of fulness and throbbing of the head were perceived. After 43 minutes he felt "abnormal" ; there were slight hyperpnce $x$ and marked intracranial throbbing. After 54 minutes the same feelings continued, but in addition there was some interference with vision, with some giddiness. After 71 minutes, when the experiment was stopped, vision had become dim, the limbs weak, movements being unsteady and uncertain, so that he had some difficulty in rising and walking without assist. ance. Six minutes after he had been breathing fresh air he staggered in walking and nearly fell, was very uncertain in his gait, and grasped uncertainly at objects for support. Vision was so indistinct even then that he could not perceive details of objects looked at. After 13 minutes he inhaled oxygen. "The effect," says be, "seemed to be distinct. After three or four seconds everything seemed to clear up suddenly and I was able to walk steadily up and down the room carrying the bag. I breathed the oxygen for two minutes, and, on ceasing, continued to walk, and soon again became unsteady and confused." Twenty-two minutes after stopping the inhalation of the carbonised air, and notwithstanding the immediately beneficial effects of oxygen inhalation, his walking still remained unsteady and vision and hearing were both defective. "At this point," he adds, "I again began to breathe from the oxygen-bag, and the effect seemed distinct. On stopving the oxygen, I again began to feel confused after about a minute of walking. On trying to run. vision rapidly became dim, and movements uncertain." During the whole of the evening of the day of experiment he suffered from headache, not accompanied, however, by nausea or loss of appepite. The headache persisted slightly during the succeeding day. From these experiments, personally borne and decribed by this skilled observer, it is quite clear that dissociation of the carbon monoxide from the hæmoglobin did not take place during the periods of inhalation of oxygen, as shown by the recurrence of the symptoms. All that presumably did happen was that the corpuscles which were able to absorb and carry oxygen took up that gas in more than normal amounts for the time being, but with evanescent effect only. This subject has been discussed because of the important practical bearing it has relative to the treatment of those asphyxiated by carburetted water gas or by any combination of gases of which carbon monozide is one of the principal constituents.

1 Pfliger's Archiv, vol. v., p. 24. 2 Archiv für Experimentelle Pathologie, vol. xxii.. p. 236.
Cases of Carburetted Water Gas Poison ing.

Professor Lorrain Smith ' has recorded a series of cases of poisoning by illuminating gas which occurred in Belfast in the years 1898 and 1899. The gas supplied to that city is a mixture of ordinary coal gas with about 40 per cent. of carburetted water gas. The mixture contains about 16 per cent. of carbon monoxide. The body of the first victim showed externally the effects of inhalation of carbon monoxide, the lips being pink in colour, as well as the skin of the dependent parts of the body. A large amount of froth was present about the mouth and nostrils. The intestines sbowed on internal examination a diffused scarlet tint. A few drops of the blood allowed to fall into water exhibited the characteristic pink tint of carboxy-hæmoglobin and when examined by the carmine method it was found to be saturated to the extent of 83 per cent. with carbon monoxide.

In the second occurrence three persons were involvedviz., a maid-servant and two children. The maid and one of the children, aged four years, were dead when found, the other child being alive and recovering after treatment. Post-mortem examination of the body of the maid showed that the lips and conjunctivæ were pale; there was froth at the mouth and nostrils; there was a bluish-pink lividity of the dependent parts of the body; and the stomach and intestines were pale pink in colour. The blood showed saturation by carbon monoxide to the extent of 76.6 per cent. The body of the child exhibited similar appearances, but the degree of saturation was only 69.5 per cent. A young man, who slept in a room adjoining that in which the above persons slept, but which was separated from it by a lath and plaster partition, suffered also from the effects of the gas. He, however, was able to move about when found, but 24 hours afterwards had no recollection of the occurrence, or even of his having been taken to hospital.

In the third occurrence two cases were involved, and both persons died. One was an old woman of 72 years of age and the other was a young child. The blood of the woman showed carbon monoside saturation to 57 per cent., and that of the child 5 per cent.

In a public work in Glasgow, a man applying for temporary employment was set to work to free from "scale" and clean the interior of a retort. He started operations about $630 \mathrm{~A}$ M. When the signal for breakfast was given at 9 A.M. he did not emerge from the retort, whereupon the foreman, thinking that this man did not $\}$ ear the ordinary signal, rapped loudly on the outside of the retort with a hammer and left for breakfast. On lis return he was told that the man had not yet come out of the retort, when search was made inside. The man was found lying dead, his naked lamp burning not far from where he lay. The day following I made a post-mortem examination of the body for the Crown. It was that of a vigorous, well-nourished man, about middle life. Externally, over nearly the whole front aspect, it bore the characteristic rosy-pink colouration of carbon monoxide poisoning, and internally the u ual pink suffusion of the inte:tines and arterial hue of the blood. Spectroscopic examination of the blood proved the presence of carboxy-hæmoglobin and further testing showed a high percentage ( 75 per cent.) of saturation. Evidence given at the Fatal Accidents Inquiry showed that this retort was part of a producer-gas plant, but it was stated that at the time the man was employed at $n$ ork in it it was not in connexion with the rest of the plant. A verdict of "Suffocation from gas fumes" was returned by the jury.

Dr. W. J. Thompson of Dublin, in the record of a case of carbon monoxide poisoning from coal fumes, mentions incidentally that he has had also under his care two cases of poisoning by Dublin illuminating gas "which, as is well known, is charged with carburetted water gas sometimes to the extent of 16 per cent., whereas in ordinary coal gas the percentage is rarely more than 6 per cent." ". These figures are probably intended to express percentages of carbon monoxide, since according to the Government Return Dublin adds 47 per cent. of carburetted water gas to its ordinary product.

l'ases of coal gas asphyxia.-It has been my lot to see a relatively large number of cases of coal gas poisoning but of these I shall only draw upon certain typical cases to illustrate different points.

CASE 1.-This occurrence involved the death of seven 
persons. On Jan. 12th, 1895, I was called as police surgeon by the police to attend at a house in which it was feared some mishap had occurred, as the occupants were not astir as usual and had not been seen all the morning, and especially because an oppressive odour of coal gas was perceptible in the lobby or passage leading to the one apartment therein. This apartment, which was situated in the sunk or area flt of a four-storeyed tenement, and which with propriety might be termed a cellar dwelling, was inhabited by a husband, wife, and five caildren of varying ages. The door was burst open by the police. At once an overwhelming atmosphere of coal gas met us as we tried to enter. A constable rushed into the apartment and succeeded in rapidly opening the one window of the room and thereafter in making his escape. After a short interval, ventilation through the apartment having in the meantime been established between the door and the window, we entered. The occupants were all found in bed. They occupied three different beds. A very hasty examination showed that there were seven persons present: the father, mother, and five children whose ages ranged apparently from 12 years downwards. Of these, the father only showed signs of life. He was quickly removed to the infirmary The bodies of the dead wife and children bore different appearances externally. That of the mother showed a pale face with a slightly bluish pallor of the lips, but there were no rosy-pink patches externally on the body. Trat of a boy, aged 12 years, showed a pale placid face with no lividity, but the tongue, slightly bluish in tint, protruded for about half an inch beyond the line of the teeth. That of a girl, aged 10 years, exhibited the same facial conditions Bile-stained marks were found on the right cheek and on the pillow, as if from vomiting. That of another girl, aged six years, whose face was generally like those of the others, except that there was mucous froth at the mouth and nostrils, showed like bodily appearances. The bodies of the others were similar. The appearances of the father were as follow. He was deeply comatose and insensible to all forms of stimulation. The body was cold to the touch. There were clammy sweat on the face and mucous froth at the mouth. The pupils were markedly contracted. Respirations were regular in rhythm and deep in character. The action of the heart was feeble. 'The skin of the body generally was pale and cold to touch. On arrival at the hospital he was almost pulseless, was breathing heavily, expiration being puffing in character. The pupils were contracted and did not respond to light, the conjunctival reflex being absent. Froth was collected about the lips. The body was cold, although the temperature registered was $996^{\circ} \mathrm{F}$. After measures had been used to restore the body heat and after the body had become warm profuse perspiration broke out all over the body, but especially on its upper part. The pulse improved in quality and the breathing calmed down. After inhalation of oxygen, the cyanosis disappeared largely from the face. Abont one and a half hours after admission the conjunctival reflex returned, as did also the mobility of the pupil, which enlarged to medium size and showed capability to contract to light. He could now be roused to a partial degree of consciousness-that is, when the conjunctiva was touched he moaned and turned away his head. This, however, was the nearest approach to consciousness which he exhibited while he lived. In the evening the breathing again became laboured and the cyanosis of the face became more marked. The extraordinary muscles of respiration were now brought strongly into action, and during expiration there was considerable puffing of the cheeks. The pulse still remained good. The body was bathed in perspiration. Physical examination of the chest now revealed dulness at the base of the left lung, but on auscultation only wheezing and crack]ing râ'es were heard at the left base and also at the right base. Froth still continued to form and collect about the lips. Oxygen inhalations were continued from time to time and hypodermic injections of sulphuric ether were also periodically administered. He lingered in this condition until the evening of the day following his admission, when he lied. His temperature, which on admission was $99 \cdot 6^{\circ}, r^{\prime} s$ that same night to $101 \cdot 6^{\circ}$, fell by next morning to normal, but again rose to that on admis-ion, and was normal at the time of death. Post-mortem examination of the body revealed dark, thick, fluid blood throughout the venous system; the internal organs were healthy. The chambers of the heart contained thick, glutinous, dark fluid blood. The base of the right lung showed passive hy peræmia, as did also that of the left, but not so marked. The blood under the microscope was seen not to form rouleaux. A noteworthy feature in the apartment in which these deaths took place was that a paraffin lamp was found burning on a low shelf not far from the beds in which the bodies were lying and the appearance of its flame did not betoken any insufficiency of oxygen. A similar fact is recorded by $\mathbf{M r}$. Jones ${ }^{6}$ of an apartment in which were found two persons asphyxiated from coal gas, one being dead and the other alive and recovering later. Another interestir $g$ feature of the foregoing case above narrated was that there was no gassupply laid into the house-indeed, there was no gas connexion of any kind, so that the source of the gas must have been outside of the building. For some time before the occurrence severe frost had prevailed and for some distance downward the earth was frost-bound, a condition apt to produce fracture of pipes. Examination of the pipes in the ground in the vicinity of the building revealed the fact that a gas pipe of one and a half inches in diameter bad been fractured, probably by the frost, and that the escaping gas had found its way into the basement apartment in question through the earth and through cracks and seams in the walls.

CASE 2.-Six days later, on Jan. 18th, I was called to deal with another series of coal-gas poisonings involving five persons, but happily without loss of life. This was probably due to the fact that the father happened to be awakened during the night by sounds which on rising to investigate be found to be caused by his children retching and vomiting. In the room in which they slept he found an almost overpowering odour of gas. The children were partly unconscious. His wife was also in a dazed condition. $\mathrm{He}$ promptly removed them from the house. Two persons living in the filt above were also affected. They chanced to be awakened by the noises produced by the excited movements of the persons below. In a few days all of them had quite recovered In this case also the cause of the mischief was a fractured pipe.

Case 3.--In November, 1900, I was asked by the late Dr.J. Finlayson, physician to the Glasgow Western Infirmary, to see with him a patient who had been admitted to his wards alleged to be suffered from coal-gas asphyxiation. She was then deeply comatose. Towards evening she developed Cheyne-Stokes breathing, the aprceic interval lasting for 11 seconds. I examined her blood by the micro-spectroscope and found undoubted eviderce of carboxy.hæmoglobin. She recovered in a few days.

In addition to these cases I have seen others, and throughout medical literature cases have from time to time been recorded. Pettenkofer, in a paper on Coal-gas Poisoning in the journal Nord und Süd, January, 1884, gives several examples of deaths occurring in persons in apartments from leakages or fractures of gas-pipes in the ground outside the dwellings. ${ }^{7}$ At Glossop in January, 1884, four persons met their death from coal gas, the cause being a fractured pipe situated two inches below the surface of the ground and about six feet from the house. The pipe was supposed to have been broken by a loaded cart which had passed over it the day before. The gas gained entrance into the house by an untrapped slopdrain pipe. ${ }^{8}$ On March 11th, 1905, seven persons were overwhelmed by coal gas in a house near Motherwell, Lanarkshire, of whom one was found dead and two others were not expected to recover. It was believed that the escape of gas was due to fracture of a pipe in the earth caused by subsidence from mining operations-a not infrequent occurrence in that neighbourhood.

It ought to be noted in passing that in every large gassupply an enormous annual loss by leakage occurs from underground pipes, as well as from defective house-pipes and fittings. According to Dr. Bayley ${ }^{9}$ the normal average leakage of gas in the cities of New York State per annum per mile of mains was 225,000 cubic feet, and in London, based on a statement by the Board of Underwriters, it amounted to 1748 millions of cubic feet per annum over the whole area of supply.

\section{Cases of Carbon monoxide Porsoning from Solrces OTHER THAN COAL GAS.}

CASE 1.-The following case is in several respects of unusual interest, and although it had no relation to water

${ }^{6}$ Erit. Med. our., vol. ii., 1896, p. 1443.

7 Popu 7 are Vorträge, vol. iii., p. 87 ; Brit. Med. Jour., vol. i., 1884, p. $822 . \quad \quad 8$ Brit. Med. Jour., vol. i., 1884, p. 121. 9 Vide note 4, supra. 
gas the gas inhaled was rich in carbnn monoxide. In an inhabited street in the east end of Glasgow is a limeburning work consisting of three kilns, one, at least, of which abutted within a few inches of the brick-built gable end of a newly-erected tenement of three storeys in height. On each flat there were three occupancies, which were tenanted by different families. During the night of Nov. 30th, 1899, the husband of the family occupying the two apartments on the ground floor nearest the gable wall returned from his work about 2 A.M. On entering his house he perceived what he described as a sickening smell. He found his wife and three children sick in bed, the children being partly unconscious. They were removed to a neighbouring house where they stayed over the night. Next morning they were practically well. Their neighbours in the flat above them, however, had not been seen since the night before and as vigorous rappings at their door elicited no response the police were sent for, who, procuring a ladder, entered the house by a window. It was then discovered that a woman and her two children were lying dead in the bed of the back apartment, and that a man-a lodger-who was occupying the bed in the front apartment was deeply unconscious but still alive. He was at once removed to the infirmary. As medicolegal examiner in Crown cases I made post-mortem examinations of the bodies of the woman and her two children. The children were aged four years and one and a half years respectively. The examination revealed the woman to be about eight months pregnant of twin children. Externally ber body bore the rosy pink colour on the left side of the face, the extensor surfaces of the arms, and on the inner and fron aspects of the thighs in the neighbourhood of the genitals. Internally, with the exception of the contents of the right ventricle of the heart, which consisted of a few dark-coloured soft coagula, the blood of the body was markedly cherry-red in colour. There was no organic disease found. The bodies of the two children, which were found lying beside that of their mother, bore generally the same external appearances and therefore were not dissected. I examined the blood of the woman spectroscopically and by other tests and found unmistakeable evidence of carboxy-hæmoglobin, the degree of saturation being about 70 per cent.

The following is the history of the man who was removed from the house to the infirmary, for the notes of which I am indebted to Dr. G. S. Middleton, physician to the infirmary. The patient was admitted at $945 \mathrm{~A} . \mathrm{M}$. on Dec. 1st, 1899, in an unconscious condition, reported to be suffering from coalgas poisoning. When admitted, the face was livid and the veins of the neck were very prominent. The pulse could scarcely, if at all, be felt, and the breath sounds were very feeble. Artificial respiration had been carried out by the ambulance attendant from the time he saw the patient until his admission into the ward and it was sustained until the oxygen apparatus was prepared. Hot bottles were put to the feet, which were cold to the hand, and a large poultice of linseed and mustard was applied over the region of the heart and upper chest. Oxygen inhalations were given for fully 20 minutes. The effect of the oxygen was purely momentary; the colour of the face improved slightly, but the improvement did not persist when the oxygen was with drawn. There was a rotatory spasm of the arms, the rotation being inwards, with the hands clenched. The knee-jerks were greatly exaggerated. Ankle clonus was easily elicited and on nolding the wrist there was a clonus as marked as at the ankle. The breathing was stertorous and there was some spasm of the muscles of the thorax. The diaphragm seemed to move normally and yet almost no air seemed to enter the lungs. The jaws were clenched tightly. The eyelids opened and closed rhythmically with inspiration and expiration. The pupils did not react to light and were quite insensible to touch. After he had been under treatment for about half an hour he could be roused by pinching to the extent of opening his eyes and removing himself from the source of irritation. Sulphuric ether was given hypodermically in repeated doses of 20 minims. Two pints of saline solution (one drachm of sodium chloride to 20 ounces of water boiled and cooled to $100^{\circ} \mathrm{F}$.) were injected by means of a needle attached to a syphon arrangement into the left gluteal region and both axillæ, but without much appreciable beneficial effect. It was only when the median basilic vein of the left arm was opened and three ounces of blood had been withdrawn that the pulse became fuller and less feeble. The effect of venesection was very striking. The quantity of blood withdrawn was small, for it ceased to flow after three ounces had been obtained, but improve ment followed immediately. Poultices were kept periodically applied to the chest till 1 P.M., when the patient began to perspire ; and by 1.30 P.M. perspiration had become profuse all over the body, and the lividity of the face had much lessened. The pupils now responded to light and the patient appeared sensible to touch. At 2 P M. he uttered a monosyllable or two in reply to a question put to him, but the meaning of what he said could not be made out. From that hour onwards he seemed to improve. He became gradually more conscious, although he remained somnolent all the afternoon and evening, but was rousable. At $11.30 \mathrm{P}$ M. 22 ounces of urine were drawn off by catheter. The urine was pale in colour, of specific gravity 1022, and contained a trace of albumin, but no blood or sugar. Granular tube casts were, however, found. During the night he twice passed urine involuntarily in bed. He was very restless and llept little. He was still stupid and could give little account of himself beyond his name. The note in the clinical record of Dec. 4th is that the patient had now quite recovered consciousness, but said that he did not remember anything that happened on the day previous to admission. He was dismissed well a week after

Among other causes of carbon-monoxide poisoning must be mentioned fumes from stoves, burning or smouldering refuse coal-heaps, gas geysers or gas heaters, and the manufacture of nickel carbonyl. The first is by no means infrequent in France from flueless or other stoves in which charcoal or coke is used and has given rise to accidental as well as suicidal deaths. One of the most noteworthy cases of this is the death of the famous novelist, M. Zola, the facts of whose death may be reciter briefly as follows. Against the return of M. and Madame Zula to their house in Paris a fire of "patent fuel," blocks of compressed charcoal, hıd been lit in their bedroom during the day to warm the room. The servant observed that the chimney did not draw, the cause, found later, being fallen mortar. The servant, after opening the window of the room, left the fire to go out. I appears, however, to have smouldered all night, as next morning the grate was found to be still hot. That morning, the servant receiving no answer to his knocking at the bedroom door, broke in the door. M. Zola was found lying dead on the floor and his wife lay unconscious on her bed. Madame Zola recovered and was then able to state that she awoke in the night feeling ill, and, though faint, was able to go to her dressing-room. On returning she spoke to her husband who also seemed ill. Later she hearả him rise from bed and fall on the floor. She tried to call for assistance but lost consciousness. Two dogs who were in the room escaped with their lives. M. Girard examined samples of blood from the body of M. Zola, as well as from Madame Zola and one of the dogs, and found conclusive evidence of the presence of carbon monoxide. From the whole circumstances it was thought that the proportion of this gas in the air of the room was probably never higher than about 0.3 per cent. ${ }^{10}$ In this connexion, also, may be mentioned ignited charcoal-dust carriage foot warmers as a source of fatal poisonings. ${ }^{11}$

Another not uncommon type of the poisonous effects of gas fumes is as embodied in the following case. The victim was a male cook in one of the river Liffey dredgers. $\mathrm{He}$ retired at night as usual for sleep into the skipper's room and, after entering, he closed and bolted the door of the room, which had a cubic capacity of 952 feet. The only source of ventilation was by this door; consequently by his act he cut off his source of air-supply. The room was warmed by a small stove, and the time of the year being November and the weather cold he put on the fire a large lump of steam coal. Not being astir at his usual time in the morning, and no reply being elicited after loud and continued knocking, the door was burst open. He was found lying on the floor deeply insensible but was removed to hospital. On admission, the colour of his face and body was "dusky, dark, and greyish"; his breathing was short, shallow, and stertorous, the respirations numbering 24 per minute; the surface of the body was very cold, although the temperature per rectum was $99 \cdot 6^{\circ} \mathrm{F}$, and the pulse was thready, small, easily compressible, and could not be counted. The heart sounds were almost inaudible; the superficial reflexes, including the conjunctival, were lost ; the pupils were irregular, the right being slightly dilated, the left contracted, and both insensitive to light; there was well-marked rigidity of all the muscles of the body, notably those of the arms; and the 
blood when drawn off had the bright red cherry-like colour of carbon-monoxide poisoning. He regained consciousness the same afternoon and thereafter quickly recovered. The treatment employed by Dr. Thompson, who records the case, ${ }^{12}$ was the continuous use of inhalation of oxygen, artificial respiration, hypodermic injections of etber, strychnine and digitalin, with electricity along the phrenic nerves and spine.

Another source of fatal poisoning is from the use of gas geysers or gas-heaters used in bath-rooms. Many cases have already been recorded. Recently another case occurred in Glasgow, the victim being a vigorous young adult who was fond of bathing. To enable him to enjoy this he himself fitted a gas-heater in his bath-room which was a small and poorly ventilated apartment. He was found dead in the bath, his head resting against the side of the bath above the level of the water.

There are also certain industrial sources from which carbonmonoxide poisoning may arise-viz., in ironworks where ammonia plant is installed and in the manufacture of nickel carbonyl. Of the former of these, the following is an illustrative example. At 2 A.M. of March $20 \mathrm{th}, 1895$, a workman employed at the Clyde Ironworks was found lying in front of one of the flues of the ammonia plant apparently dead. He was only insensible, however; but his face was ghastly pale, his eyes were staring and glassy, his pupils were fixed and dilated, his breathing was quiet and shallow, and his pulse was slow but fairly strong. He could not be roused. After treatment he began to show signs of animation and to speak incoherently. Soon thereafter he was attacked with clonic convulsions, which lasted for about two hours, the muscles of the left side being chiefly affected. About 6 A.M. he was improving, but was suddenly attacked with tetanic contractions of the muscles, chiefly the extensors of the trunk and the flexors of the limbs. Under the influence of chloroform these abated but reappeared when the effects of the drug wore off. Oxygen by inhalation was then administered but with no success. These tetanic contractions became less violent, the patient the while remaining semi-comatose. This condition of semi-coma lasted for ten days. On the fifteenth day after the accident he was suddenly seized with acute mania, which required him to be placed under restraint. Thereafter he again became comatose. Ten days later he was conscious enough to put out his tongue when asked. By May 22nd his lucid intervals had become more frequent and lasted longer. Thereafter he gradually, though slowly, improved. The gas which gave rise to his symptoms was, on analysis, found to contain over 25 per cent. of carbon monoxide. Dr. A. Scott, who records the case, ${ }^{13}$ mentions that in a neighbouring works there had been no fewer than six fatal cases from the same cause, and gives references to two other cases in which dementia followed.

Regarding the second of the above-mentioned industrial causes it is important to note that nickel carbonyl $\left(\mathrm{Ni}(\mathrm{CO})_{4}\right)$, which is a compound of nickel with carbon monoxide, is extremely poisonous. It is a clear liquid of considerable refractive power, of a specific gravity of 1.3185 at $17^{\circ} \mathrm{C}$. which is soluble in alcohol, benzene, chloroform, and olive oil, and which evaporates on exposure to the air, giving off carbon-monoxide gas. McKendrick and Snodgrass ${ }^{14}$ have investigated its physiological action after injection, and have demonstrated that it is highly toxic, not only when injected hypodermically, but also when inhaled as a constituent of the atmosphere. Their experiments indicate that a percentage less than 0.5 was dangerous to life. In 1903 two deaths in Mond's Chemical Works, Clydach, were attributed to this substance. Both men had been exposed to the vapour of nickel carbonyl. Dr. J. Jones reported that there had been 26 cases of slight poisoning among workmen under his care during the previous summer. Dr. F. W. Tunnicliffe, who examined the internal organs of one of the men, came to the conclusion that death was due to the substance already named. The post-mortem signs pointed to death by asphyxia, cedema of the lungs being present. An examination of the brain of one of the deceased men was made by Dr. F. W. Mott, who found capillary hæmorrhages throughout the substance of the organ, as well as chromolytic changes in the nerve cells of the medulla and pons, especially of the cardio-respiratory centres. ${ }^{15}$

Perhaps the most common of the industrial causes of fatal

$$
12 \text { Loc. cit. }
$$

accidents by carbon monoxide is coal-mining, from chokedamp, smouldering fires in pits of coal or woodwork in places where the ventilation is imperfect, or following the use, in similar places, of the higher explosives; but this forms so large a branch of the subject that it cannot now be more than mentioned.

Chronic Poisoning by Carbon Monoxide.

After, or concurrent with, an asphyxiating attack of poisoning by carbon monoxide there may be unexpected mental symptoms. Cases have from time to time been recorded where the impairment of the mental faculties has continued for months and sometimes for years after. Dr. Scott ${ }^{10}$ has recorded one case in which a workman engaged in connexion with the ammonia-saving plant of an ironworks, and who was found lying insensible in the close proximity to one of the flues, developed marked mental symptoms which remained for some weeks afterwards; and in his paper he speaks of a second case in which a workman, who had suffered in somewhat the same way, remained weak-minded for two years afterwards in a condition of partial dementia. Such cases are explicable on the ground of the hæmorrhagic lesions which are commonly found in the brains of those who have died from inhalation of the gas, and doubtless the incidence of such symptoms, their degree and character when present, and their duration, must largely depend on the amount and distribution of these capillary hæmorrhages.

But there is another form of chronic poisoning due to more or less constant exposure to relatively minute proportions of this gas, which is very insidious in its onset and the symptoms of which may fail to awaken suspicion as to their true cause. These symptoms may be grouped generally under the designation of a lowered condition of general health, accompanied by more or less anæmia and malnutrition. It is well known that workers in atmospheres in which, by reason of imperfect means of lighting by daylight, artificial lighting by coal gas has to be resorted to, sooner or later manifest a sallow and ill-nourished appearance, accompanied by loss of flesh, want of animation, and by a superinduced desire for stimularts, sometimes entirely foreign to the inclination of the individual. It is quite true that this line of symptoms has not as yet been proved to be solely due to the presence in the air of such places of minute proportions of carbon monoxide. but there is good ground for believing that it is largely due to this gas. It is difficult to conceive that exposure over long periods to this gas should not leave a distinct disturbance of the physiological functions of the blood, and, by consequence, disturbance of nutrition of the tissues and organs. After acute poisoning probably one organ or another of the body remains most crippled. In some cases dementia of the type exhibiting deficiency of mird rather than aberration of intellect bas followed. The ratient. seems to lack nerve and mental power, becomes apathetic, and, occasionally, weak-minded. Such a condition may well follow minute cerebral bæmorrbages into the brain substance with sequent sclerotic changes. Nor is this condition an evanescent one; in some cases it has, indeed, lasted for years. Therapeutic measures, moreover, do not seem to expedite recovery from this chain of symptoms the most they seem able to effect is to restore and maintain some degree of physical health.

The effect of the inhalation of carbon monoxide from defective apparatus on the health of those exposed has already formed the basis of an action at law in Waters and Wife $v$. The Brighton and Hove General Gas Company, which was tried in November, 1902, before Mr. Justice Lawrance in the King's Bench Division, London. It appears that in December, 1901, the defendants contracted with the plaintiffs to supply and fix in his house certain gas stoves, to connect certain pipes therein with a pipe conveying gas, and to do all necessary things to finish the work. It was further alleged that the work was done so negligently and unskilfully that, during the night of Dec. 23rd and the morning of Dec. 24th, gas escaped into the bedroom in which the plaintiffs slept "and thereby poisoned the plaintiffs and made them both ill "; that the effects on the male plaintiff were poisoning of the blood, congestion of the lung, headache, vomiting, fever, affection of the throat, and lassitude, and that for a fortnight he was unable to follow his avocation. It was further averred that the poisoning bad permanently weakened the right lung of the male plaintiff, and rendered 
it liable to attacks of congestion. It was admitted for the defendants that water gas was used by the company to the extent of 31 per cent. (It will be observed from the Board of Trade Returns for 1904 that the percentage used in that year was 38 per cent.) The plainiffs succeeded in proving negligence. In hi $i$ evidence the male plaintiff stated that when he retired to bed with his wife on the night in question he perceived an unpleasant smell in the room which he thought, however, to be due to the varnish with which the stove had been painted. He turned off the gas from the stove and retired. About 7 A.M. the following morning he remembered trying to reach the washstand in the room from the floor, on which he had fallen, as he felt sick and inclined to vomit, which he did subsequently; and that he also felt very weak and ill. About 9.30 A.M. he walked with difficulty to the offices of the gas company, about a mile from his house, to make complaint. His wife averred in the witness-stand that she awoke on the morning of the 24th feeling sick and ill ; observed her husband lying by her side; that she thought him at first to be dead, but she awoke him, and on his rising he fell on the floor. Four days afterwards, still feeling ill and unable to go to business, the male plaintiff sought medical advice. The medical man who was called gave evidence that on the date in question $(28 \mathrm{th})$ he found the plaintiff with a temperature of $101 \cdot 8^{\circ} \mathrm{F}$. and a very feeble pulse and complaining of headache, giddiness, cough, and hæmoptysis ; that examination of the lungs showed congestion of the right lung, and that the sputum on examination did not show the presence of the tubercle bacillus; and that the urine contained a trace of albumin. The medical defence for the company was to the effect that, while the lung dulness was admitted, it was not likely to have been caused by carbon monoxide poisoning. A verdict for both plaintiffs was returned. ${ }^{17}$

The only comment that need be made on this case is, that while it is neither typical of acute nor of chronic poisoning, it illustrates the crippling effect which exposure to carbon monoxide has upon some organ of the body.

\section{Treatment in Gas Poisonisg.}

Whether the kind of the gas be producer gas, water gas, carburetted water gas, or ordinary coal gas, the problem to be solved in the treatment of those deeply comatose from inhalation of the gas is how to overcome the association of the carbon monoxide with the bromoglobin and to restore the oxygen-carrying function of the red corpuscles. It will be obvious that the only difference in action of these gases is one of time, due to the differences in percentage of carbon monoxide which they respectively contain; or, in other words, because of the much less percentage amount of carbon monoxide in coal gas it takes a longer time to produce an equal degree of saturation than in the case of the others. Even in coal gas inhalation, however, when the person is found to be deeply unconscious, and particularly when ordinary remedial efforts prove unavailing, it is the toxic effects of the carbon monoxide which have to be combated. The first indication in treatment is to remove the sufferer, under suitable precautions, into the open air. By reason of the action of carbon monoxide on the vaso-motor nerves producing coldness of the surface of the body these suitable precautions ought to consist of measures calculated to restore surface warmth, which is of considerable importance. As I have said elsewhere ${ }^{1 /}$ artificial respiration will only be necessary if voluntary breathing be embarrassed or irregular. Inhalations of oxygen should be given. If in spite of these measures no sign of recovery appears, bleeding and injections of saline solution or transfusion of live human blood should be carried out. Farrab, in a paper read before the Philadelphia Pathological Society in November, 1899, stated that he found experimentally on dogs that transfusion gave good results the transfused blood being obtained from the carotid artery of a healthy dog and allowed to pass into the jugular vein, while saline solutions were only of temporary value, and hydrogen peroxide injected intravenously and subcutaneously yielded no beneficial effect. In carbon monoxide poisoning removal into the open air is not so urgently called for, although plenty of fresh air is ne sessary. The difficulty is to obtain dissociation of the gas from the hæmoglobin even by the administration of oxygen, because of the diminished capability of the red corpuscles to absorb and carry oxygen.

17 Journal of State Medicine, vol. x , Na. 12. 1902, p. 729.

18 Text-book of Medical Jurisprudence, Toxicology, and Public Health, p. 463.
While artificial respiration, oxygen inhalations, and measures for the restoration of body heat ought to be persevered in until, at least, the animal neat is restore l, should no further improvement be manifested, bleeding and transfusion should be resorted to.

Glasgow.

\section{SOME CASES OF ACUTE LEUKFMIA ADMITTED INTO ST. GEORGE'S HOS- PITAL BETWEEN 1895 AND 1905.}

\section{BY L. D. BAILEY, M.R O.S. ENG., L.R.C.P. LOND.,} LATE HOUSE PHYSICIAN, ST. GEORGE'S HUSPITAL.

CASES of acute leukæmia are still of such rarity that their publication demands no justification. While acting as house physician at St. George's Hospital I was fortunate enough to see three cases of this interesting disease. The patients were all admitted during the months of August and September, 1905 , and within a fortnight of one another. On searching the hospital records during the previous ten years for similar cases I found notes of two which I include in this series. The cases were under the care of the following physicians:Case 1, Dr. W. Ewart; Cases 2, 3, and 4, Dr. H. D. Rolleston and Dr. J. S. Collier ; Case 5, Dr. A. Latham. I am greatly indebted to these gentlemen for permission to publish them, and for many valuable suggestions regarding them.

CASE 1-The patient, a female, aged 18 years, was admitted as an in.patient on Dec. 20th, 1898. Three months before admission she had noticed a swelling about the angle of the left side of the jaw which was followed by an enlargement of the glands in the anterior and posterior triangles on both sides of the neck. The glands in the right groin also became enlarged but subsequently this enlargement sub. sided. One month before admission to hospital both tonsils had been removed and several teeth had been extracted from the left lower jaw, presumably because they were carious. The patient had been short of breath since the onset of illness, but had never noticed any odema. During the week before admission there had been several attacks of hæmoptysis and hæmatemesis, about one pint of blood being lost in all. The patient had become very deaf during the last few days and three days before coming to the hospital had first noticed the appearance of purpuric spots on the limbs and the trunk. There was no history of diarrbœa or melæna or of traumatism. The patient's own history and that of her family contained nothing of importance. The catamenia had been absent for the preceding three montbs.

On admission the patient was found to be fairly well nourished but anæmic. There were general puffiness of the eyelids and the face and faucial anæmia; the tonsils were somewhat swollen, the right one having a bleeding surface. No stomatilis was present. There was a copious eruption of petechial spots on the upper and lower limbs as well as a few ecchymoses of considerable size. There was some staining of the left lower eyelid and a few purpuric spots were noticed on the trunk and the neck. All the lymphatic glands of the neck were enlarged, but for the most part they were discrete. Under the angle and the ramus of the lower jaw on the left side was a collection of glands of the size of a hen's egg. The glands in the axillæ were palpable but quite small. The antecubital glands were not felt. One gland in the right groin was as large as a walnut; the others were but slightly enlarged. The heart sounds were normal. The pulse was 120 and soft and regular. Orer the upper part of the sternum there was increased dulness; otherwise the lungs appeared to be normal The respirations were 28. On examining the abdomen some epigastric tenderness was manifest but no enlargement of the abdominal glands was made out. The edge of the spleen was palpable on deep inspiration under the left costal arch. The liver dulness was increased downwards one finger's breadth, but the edge was not felt. There was no tenderness of the bones. The urine contained blood and a slight amount of albumin. The bowels were constipated.

An examination of the blood was made one day after admission when the white corpuscles were found to number 53000 per cubic millimetre and the red corpuscles $3,860,000$ per cubic millimetre. A differential examination of 1000 white cells gave : polynuclear cells, 25 ; eosinopbile cells, 4 ; and lymphocytes, 971 . The lymphocytes were of varying shapes; the majority, about 90 per cent. of the white cells, 